\title{
A Comparison Between Dissection-Method And Diathermy Tonsillectomies in Rims, Ranchi
}

\author{
Dr. Rajesh Kumar Choudhary ${ }^{1}$, Dr. Pradeep Kumar Singh ${ }^{2}$, \\ Dr. Nisha Shrivastava ${ }^{3}$ \\ ${ }^{I}$ Assistant Professor, Department Of Otorhinolaryngology, Rajendra Institute Of Medical Sciences, Ranchi. \\ ${ }^{2}$ Associate Professor \& Head, Department Of Otorhinolaryngology, Rajendra Institute Of Medical Sciences, \\ Ranchi. \\ ${ }^{I}$ Junior Resident, Department Of Otorhinolaryngology, Rajendra Institute Of Medical Sciences, Ranchi.
}

\begin{abstract}
:
Introduction: Tonsillectomy is one of the most commonly performed operations in otolaryngology. There are many proven methods of tonsillectomy, including cold dissection and bipolar electrocautery. The objective of this study is to compare the dissection and diathermy methods of tonsillectomy and evaluate their advantages and disadvantages during surgery and convalescence.

Material and Method: The study included 50 children who underwent tonsillectomy during one period of time. This study was carried out at Rajendra Institute of Medical Sciences, Ranchi. Patients were randomly selected to have either the right or left tonsils removed by either technique (cold dissection or monopolar dissection technique). We compared both techniques in each side on the same patient.

Results: The average amount of bleeding on electrocautery side was $37.2 \pm 2.46 \mathrm{ml}$ and on the cold dissection side was $83.7 \pm 3.37 \mathrm{ml}$. The mean time of operation for electrocautery and cold dissection was $11.1 \pm 0.39$ and $18.11 \pm 0.65$ minutes respectively. On the second post operative day, $38 \%$ of the patients complained of pain on the cauterized side, $28 \%$ complained of more pain on the dissection side while $34 \%$ experienced equal pain on both sides. Post-operative complication such as hemorrhage was not seen in both the techniques employed.

Conclusion: The bipolar electrocautery appears to cause less bleeding and postoperative pain and it seems to be less time consuming in compare with the cold dissection tonsillectomy,. but patients experience slightly more pain than cold dissection.
\end{abstract}

Keywords: tonsillectomy, bipolar electrocautery, cold dissection.

\section{Introduction}

Tonsillectomy is one of the commonest surgical procedures performed in the field of otolaryngology. Tonsillectomy was described for the first time by Celsius in the first century $\mathrm{AD}^{1}$. There are several existing techniques to perform tonsillectomy, including cold dissection, guillotine excision, cryosurgery, ultrasonic removal, laser tonsillectomy, and monopolar and bipolar diathermy dissections. Ideally, the procedure to be employed should be fast, safe, painless, and bloodless, and associated with rapid recovery. ${ }^{2}$ In spite of all the new surgical tools and techniques hemorrhage is still a significant complication during and after tonsillectomy and about $5 \%$ patients may face this problem at any time from first 24 hours to 10 days after operation. ${ }^{3}$

The use of monopolar diathermy in tonsillectomy was first introduced by Haase and Noguera ${ }^{4}$ and Johnson. ${ }^{5}$ Use of bipolar diathermy, although decreases the time to control the bleeding, is always associated with a danger of necrosis and infected slough formation which may lead to secondary hemorrhage. ${ }^{6,7}$

This study concerns two popular methods: bipolar cautery excision and dissection/snare followed by compression with gauge piece and selective cautery of bleeders.

\section{Materials And Methodology}

Fifty children were recruited for this study during the period of one year at Rajendra Institute of Medical Sciences, Ranchi. Children between the age of 5 and 15 years listed for tonsillectomy were included. Children were recommended not to have aspirin within the 2 weeks before surgery. Children with acute tonsillitis 6 weeks before surgery, the indication of malignancy or peritonsillar abscess, history of blood or cardiovascular disease and those with bleeding disorders were excluded from this study.

It was a prospective single blind controlled study to compare the two methods in terms of intraoperative time, intraoperative bleeding, post operative pain and post operative hemorrhage. It was a singleblind study, as patients were aware of the operation technique but were not aware on which side the technique was used. The operation procedure was explained to the patients before the surgery and their written consent was obtained. All the operations were done under general anesthesia. In one site of tonsil tonsillar dissector and 
snare were used and haemostasis was achieved by packing whereas in the other tonsil bipolar electrocautery was used. Intraoperative bleeding on the each side was recorded by measuring the amount of blood in milliliters collected in the suction bag and $19 \mathrm{~cm} \times 14 \mathrm{~cm}$ size of standard gauge was used. The blood loss was $4 \mathrm{ml}$ if the gauge piece was fully soaked and it was $2.5 \mathrm{ml}$ if gauge piece was partially soaked.

Throat pain was evaluated by asking the patients about the side of the tonsillectomy they had more pain on the first operative day. Operation time was also measured for each tonsil. Data analysis was done using simple frequency and percentage.

\section{Results}

Using the electrocautery, the right side was operated in 31 patients and the left side was operated in 19 patients. The average amount of the bleeding in cauterized side was $37.2 \pm 2.46 \mathrm{ml}$ and on the other side was $83.7 \pm 3.37 \mathrm{ml}$. The maximum amount of bleeding on the cauterized side was $100 \mathrm{ml}$ and minimum amount of bleeding was $10 \mathrm{ml}$. On the other side, maximum and minimum amounts of bleeding were $130 \mathrm{ml}$ and $20 \mathrm{ml}$, respectively

The mean time of operation on the cauterized part was $11.1 \pm 0.39$ minutes and on the other side was $18.11 \pm 0.65$ minutes

On the second day after the operation, $38 \%$ of the patients had pain on the cauterized side and $28 \%$ had more pain on the other side and $34 \%$ had equal pain on both sides.

We observed time taken for dissecting the tonsil was short in the classical dissection method but time taken in controlling haemostasis in the same method was more which led to an overall increased operating time in this method. Whereas in case of electrocautery, haemostasis was achieved as the tonsil was dissected out.

\section{Discussion}

Using the electrocautery to remove tonsils has been the most common method in the United States since 1930. The monopolar and bipolar electrocautery may be used for tonsillectomy. However, the bipolar electrocautery transfers to a smaller part of the tissue. Therefore, the spread of heat to the tissue and its environment is less ${ }^{8,9,10}$. Due to the fast recovery and less pain in the mechanical method which lead to the more protection and less damage to the tissue, it was believed that cold dissection was preferred to the other method 10. Due to the tissue damage and heating injury of the electrocautery which may create pain after operation, epithelialization in surgical bed may be delayed ${ }^{10}$.

The average amount of bleeding on electrocautery side was $37.2 \pm 2.46 \mathrm{ml}$ and on the cold dissection side was $83.7 \pm 3.37 \mathrm{ml}$ showing a significant lower intraoperative bleeding which is in agreement to other studies $^{11,12}$.

Weimert et al, ${ }^{13}$ noted a decrease in operative time by using the cautery technique, average 2.5 minutes for the cautery side and 6 minutes for dissection/snare side. Mann et al, ${ }^{14}$ noted an average of 10.1 minutes for the cautery side and 12.4 minutes for the dissection side. However, Leach et al reported a decreased operative time with the cold technique, (13.5 versus 9.9 minutes $){ }^{2}$ while in our study mean operative time for cautery technique was $11.1 \pm 0.39$ minutes and for dissection method was $18.11 \pm 0.65$ minutes.

Postoperatively the patients experience more pain in electrocautery which is similar to the study by Kirazli et al ${ }^{15}$ but differ from Kousha et al $^{16}$ where pain was more in classical dissection method and equal pain was observed in a study by Raut et al. ${ }^{10}$

\section{Conclusion}

In the present study, bipolar diathermy tonsillectomy had advantages in having less post operative time and blood loss intraoperatively but patients experience slightly more pain than cold dissection.

\section{References}

[1]. McAuliffe CJ. The history of tonsil and adenoid surgery. Otolaryngol. Clin. North Am., 1987;20:4 15.19.

[2]. Leach J, Manning S, Schaefer S. Comparison of two methods of tonsillectomy. Laryngoscope 1993; 103: 619-622

[3]. Randall DA, Hoffer ME. Complications of tonsillectomy and adenoidectomy. Otolarygol Head Neck Surg. 1998; 1: 61-68

[4]. Haase FR, Noguera JT. Haemostasis in tonsillectomy. Arch Otolaryngol 1962; 75: 125-126.

[5]. Johnson F. Electrocautery in tonsil and adenoid surgery. Arch Otolaryngol 1962; 75: 127-129.

[6]. Carmody D, Vamadeva T, Cooper SM. Post tonsillectomy haemorrhage.J Laryngol Otol. 1982;88: 117-21.

[7]. Brown PM, Fowler S, Ryan R, et al. ENT day surgery in England and Wales: an audit by Royal College of Surgeons of England. J Laryngol otol.1998; 112: 161-65.

[8]. Dyleski RA, Dennis M. Tonsillitis, tonsillectomy and adenoidectomy. In: Byron J Bailey, Byron J Bailey, Norman Friedman, Norman Friedman, Jeffrey T Vrabec, editors. Atlas of Head \& Neck Surgery-Otolaryngology. 2nd ed. Lippincott Williams \& Wilkins; 2001. 979-993.

[9]. Paradise JL. Tonsillectomy and adenoidectomy. In: Bluestone CD, editor. Pediatric Otolaryngology. 4th ed. Philadelphia: Saunders; 2003. 1210-1222.

[10]. Raut V, Bhat N, Kinsella J, Toner JG, Sinnathuray AR, Stevenson M. Bipolar scissors versus cold dissection tonsillectomy: a prospective, randomized, multi-unit study. Laryngoscope 2001; 111(12):2178-2182. 
[11]. Pang YT.Paediatric tonsillectomy: bipolar electrodissection and dissection/snare compared. The Journal of Laryngology \& Otology (1995), 109:733-736.

[12]. Bersin S,Kutluhan A,Yurttas V,Bozdemir K,Yalciner G.Comparison between bipolar cautery dissection and classic dissection techniques in tonsillectomy.Kulak Burun Bogaz Ihtis Derg. 2008;18(1):24-30.

[13]. Weimert TA, Babyak JW, Richter HJ. Electrodissection tonsillectomy. Arch Otolaryngol Head Neck Surg 1999; 116: 186-188.

[14]. Mann DG, St George C, Scheiner E, Granoff D, Imber P, Mlynarczyk FA. Tonsillectomy some like it hot. Laryngoscope 1984; 94 : 677-679.

[15]. Kirazli T, Bilgen C, Midilli R, Ögüt F,Uyar M and Kedek A.Bipolar electrodissection tonsillectomy in children.European Archieves of oto-rhinolaryngology. 2005;262:9.

[16]. Kousha A, Banan R, Fotoohi N, Banan R. Cold dissection versus bipolar electrocautery tonsillectomy.Journal of Research in Medical Sciences. 2007;12:117. 